\title{
POLÍTICAS DE LÍNGUA E A EDUCAÇÃO DE JOVENS E ADULTOS
}

\author{
MARIA MARTINS DA SILVA MAGIO ${ }^{1}$ \\ THALITA MIRANDA GONÇALVES SAMPAIO ${ }^{2}$
}

Programa de Pós-Graduação em Linguística, Universidade do Estado de Mato Grosso UNEMAT - Cáceres/MT

mmsmagio@gmail.com, sampaio.thalita@gmail.com

\begin{abstract}
Resumo. A História das Ideias Linguísticas se caracteriza por um programa que teve início na década de 1980 e se propõe a discutir, entre outras agendas, sobre a história da língua portuguesa no Brasil. Dentro desta perspectiva, propomos neste trabalho, através dos pressupostos teóricos da Análise de Discurso, compreender como o Estado executa suas políticas de língua tomando como materialidade os documentos oficiais que versam sobre o ensino de língua em nosso país, no que diz respeito à modalidade EJA. Consideramos como materialidade significante os documentos oficiais, como artigos da Constituição Federal, os PCN - Parâmetros Curriculares Nacionais, a Lei n. 9.394/96, chamada de LDB - Lei de Diretrizes e Bases da educação nacional, Portarias da SEDUC - Secretaria de Educação do Estado de Mato Grosso, e diretrizes para a modalidade EJA - Educação de Jovens e Adultos. Palavras-chave: educação de jovens e adultos; Estado; política de língua.
\end{abstract}

\begin{abstract}
The History of Linguistics Ideas is characterized by a program that began in the 1980s and proposes to discuss, amongs other issues, the history of the Portuguese language in Brazil. Within this perspective, we propose, in this article, based on the theoretical framework of Discourse Analysis, to understand how the State executes its language policies. Therefore, we have analyzed official documents that regulates the teaching of language in our country, focusing on Education for Young People and Adults (EJA). We considered as significant materiality official documents such as articles of the Federal Constitution, the PCN - National Curricular Parameters, law $n$. 9.394/96 called LDB - Guidelines and Bases of National Education, Ordinance set by SEDUC-Education Secretary of the State of Mato Grosso, and the Educational Guidelines for EJA - Youth and Adult Education.
\end{abstract}

Keywords: youth and adult education; State; language policy.

\footnotetext{
${ }^{1}$ Mestre pelo Programa de Pós-Graduação em Linguística da Universidade do Estado de Mato GrossoUNEMAT- Cáceres/MT. http://lattes.cnpq.br/3192570960552815.

2 Doutoranda no Programa de Pós-Graduação em Linguística, da Universidade do Estado de Mato GrossoUNEMAT- Cáceres/MT. http://lattes.cnpq.br/3258958506659023.
} 
Ao pensarmos a língua por um viés materialista, pensamos então que toda materialidade se configura por uma memória, ou seja, que há algo que fala antes e que atravessa essa materialidade o que a caracteriza enquanto real. $\mathrm{O}$ mesmo se dá com a língua, há uma memória, uma história que a perpassa e a faz significar. Por esses pressupostos, nos propomos a pensar a língua fundamentada na História das Ideias Linguísticas, que se caracteriza por um estudo que tem como objeto a história da língua portuguesa no Brasil, tomando-a em seu aspecto histórico, político e ideológico, aspectos estes que se marcam em políticas de língua. Isto posto, propomo-nos a pensar de que modo essas políticas se materializam/atravessam a Educação de Jovens e Adultos (EJA). Assim podemos dizer que:

De um lado, a história das ideias linguísticas se produz nas condições determinadas em que se inscrevem a constituição da "língua nacional". De outro como a questão da "língua nacional" deriva do domínio do Estado, a produção do saber metalinguístico inscreve-se em um jogo complexo entre o papel legislador do Estado, o papel regulador da instrução e a tradição da gramática. (ORLANDI, 2001, p. 21)

Desse modo, pensando o saber metalinguístico em sua materialidade, pretendemos analisar como se dão as políticas de línguas articuladas pelo papel legislador do Estado e regulador da instituição, traçando um percurso histórico de tais políticas na Educação de Jovens e Adultos visto que, ao longo da história, a língua modifica-se. Veremos então como o Estado executa suas políticas tomando como materialidade os documentos oficiais que versam sobre o ensino de língua em nosso país, no que diz respeito à modalidade EJA.

Tomamos como objeto de análise dos documentos oficiais, sendo eles, a Constituição Federal ${ }^{3}$, os PCN - Parâmetros Curriculares Nacionais, a Lei n. 9.394/96 chamada de LDB - Lei de Diretrizes e Bases da educação nacional, Portarias da SEDUC - Secretaria de Educação do Estado de Mato Grosso e as diretrizes educacionais para a modalidade EJA - Educação de Jovens e Adultos.

Através destes documentos podemos ter acesso aos modos de como a Língua é gerida. Assim, pensando a língua discursivamente, retomamos Orlandi (1996, p. 26) ao dizer que, "quando se diz algo, alguém o diz de algum lugar da sociedade para outro alguém também de algum lugar da sociedade e isso faz parte de significação", nos perguntamos: Como o Estado, através destes documentos, regula o ensino de Língua na Educação de Jovens e Adultos?

Ao pensar em políticas de língua, pensamos nos modos como a língua é regida. E as políticas de língua no Brasil vem produzindo efeitos de sentido desde a colonização. Temos aí funcionando duas instituições reguladoras, o Estado e o Clero, como nos mostra Mariani (s/d, p. 76):

\footnotetext{
${ }^{3}$ Disponível em

http://portal.mec.gov.br/setec/arquivos/pdf_legislacao/superior/legisla_superior_const.pdf. Acesso em 30 de novembro de 2012.
} 
O objetivo conjunto Estado/Igreja de colonizar e de evangelizar definiase pelo sistema de padroado, ou seja, por um lado o papa atribuía à Coroa portuguesa atividades da hierarquia religiosa e as despesas eram tributadas ao Rei; por outro, cabia a Portugal a tarefa de evangelizar os habitantes das terras descobertas. O padroado gerava obrigações e sujeições para ambas as partes: Portugal devia evangelizar, mas o clero ficava submetido ao poder real. A única ordem religiosa que tinha mais independência, mais acesso direto ao Papa e menos subserviência aos reis portugueses, era a Companhia de Jesus. São os jesuítas que, ao longo da história da formação da sociedade colonial, exercerão um papel influente na composição das políticas lingüístico-colonizadoras tecidas pelos reis portugueses e pelo Vaticano.

Quando consideramos estes acontecimentos por um viés discursivo podemos perceber que vão sendo colocados sentidos para a língua nacional. Uma língua que vai se constituindo através do olhar do Outro, aqui pensado enquanto alteridade constitutiva, pois é uma língua que se constitui pelo colonizador. Difundir esta língua era então um modo de manter o controle do Estado. Este poder foi bem representado através do "Diretório dos Índios" do Marquês de Pombal, que interditou a língua Geral ou qualquer outra que não fosse a língua portuguesa e mais a frente, institui uma posição jurídica a este lugar ainda "indefinido" como força de Estado, "Em 30 de setembro de 1770, um novo édito é promulgado estabelecendo definitivamente o ensino de português como forma de assegurar a correção da língua" (MARIANI 2004, p. 153).

Enquanto Política de Língua, para se manter um controle, "sanar" o problema do analfabetismo já era almejado desde o início do período republicano, tendo como interesse político a questão do direito ao voto, visto que este ato era vetado aos analfabetos, como nos mostra o documento emitido pela UNESCO em 2008:

No início do período republicano, a alfabetização e a instrução elementar do povo ocuparam lugar de destaque nos discursos de políticos e intelectuais, que qualificavam o analfabetismo como vergonha nacional e creditavam à alfabetização o poder da elevação moral e intelectual do país e de regeneração dos pobres brancos e negros libertos, a iluminação do povo e o disciplinamento das camadas populares, consideradas incultas e incivilizadas. Pouco, porém, foi realizado nesse período no sentido de desencadear ações educativas que se estendessem a uma ampla faixa da população. Devido às escassas oportunidades de acesso à escolarização na infância ou na vida adulta, até 1950, mais da metade da população brasileira era analfabeta o que a mantinha excluída da vida pública, pois o voto lhe era vedado. (UNESCO, 2008, p. 21)

A intervenção política com relação a uma língua nacional volta a se repetir no período Vargas que compreende o período de 1937 a 1945, em que o Presidente decretou a Lei n. 1.545, de 25 de agosto de 1939, que versava sobre a alfabetização de estrangeiros na língua portuguesa e que se deu como uma forma de interdição às línguas de outros países como uma forma de fortalecimento nacional. Segundo Orlandi (2009), caracterizou-se por um período autoritário de forte tendência centralizadora, sustentado por um nacionalismo exacerbado e que exercia um forte controle dos meios de 
comunicação. Com relação à educação de adultos, o item 5 do artigo 85, do Decreto-lei 406, de maio de 1938, "Nas escolas para estrangeiros adultos serão ensinadas noções sobre as instituições políticas do país". Com esse decreto, o presidente instaura uma repressão aos imigrantes. Dessa forma:

Como a língua materna desempenha um papel importante na relação entre língua e nação, é contra a língua materna dos imigrantes que se lança Getúlio com seus decretos, procurando assim, com seu discurso militante nacionalista dar lugar a uma só língua materna, a brasileira, que em seu discurso é a língua nacional. (ORLANDI, 2009, p. 118)

No percurso histórico das conquistas da EJA, temos Paulo Freire, em 1963 que, juntamente com a Universidade de Brasília, desenvolveu uma pesquisa na tentativa de alfabetizar jovens e adultos trabalhadores do Distrito Federal. Mas o golpe militar em 1964, extinguiu a iniciativa institucional do governo João Goulart, proibindo assim, a prática do método de alfabetização de adultos proposto por Paulo Freire.

Em 1967 é criada pelo regime militar, a Lei n. 5.374/67 que traz a Fundação Movimento Brasileiro de Alfabetização - MOBRAL ${ }^{4}$ - que não teve êxito no que diz respeito à alfabetização, portanto foi extinto. Mas tendo Paulo Freire como mentor da educação libertadora ${ }^{5}$ de jovens e adultos e trabalhadores do DF, as iniciativas continuaram e esse movimento libertador perpassa anos de luta em prol deste modo de educação.

A Lei Orgânica do DF (1989 a 1994), no Artigo 225 assegura à EJA que "O Poder Público proverá atendimento a jovens e adultos, principalmente trabalhadores, em ensino noturno de nível fundamental e médio, mediante oferta de cursos regulares e supletivos, de modo a compatibilizar educação e trabalho ${ }^{6}$." Com esta lei, a Educação de Jovens e Adultos, no seu quadro histórico, obteve mudanças que contribuíram para que o trabalhador, impossibilitado de estudar, tivesse acesso à sala de aula.

Com o passar do tempo, a educação de jovens e adultos foi adquirindo um caráter humanizador. O relatório da V Conferência Internacional sobre Educação de Adultos, que aconteceu em Hamburgo em 1997, diz que a Educação de Jovens e Adultos tem por base o desenvolvimento do ser humano e pode ser considerada uma das chaves do século XXI. Propõe um ensino pautado no desenvolvimento sócio-histórico do aluno, levando em consideração as experiências de vida dele, ou seja, sua historicidade.

Reforçando o que apresenta a Constituição Federal, a Lei de Diretrizes Educacionais do Estado de Mato Grosso (1998), em sua sessão VI, diz em seus artigos:

\footnotetext{
${ }^{4}$ Movimento Brasileiro de Alfabetização (MOBRAL) foi um projeto do governo brasileiro, criado pela Lei $\mathrm{n}^{\circ}$ 5.379, de 15 de dezembro de 1967, e propunha a alfabetização funcional de jovens e adultos, visando "conduzir a pessoa humana a adquirir técnicas de leitura, escrita e cálculo como meio de integrá-la a sua comunidade, permitindo melhores condições de vida". Disponível em http://pt.wikipedia.org/wiki/Movimento_Brasileiro_de_Alfabetização. Acesso em 30 de julho de 2012.

${ }_{5}^{5}$ FREIRE, P. Educação como prática de liberdade. 17a . ed. Rio de Janeiro: Paz e Terra, 1979.

${ }^{6}$ Histórico da EJA: www.forumeja.org.br/DF. Acesso em 25/07/2012.
} 
Art. 84 - A Educação de Jovens e Adultos gratuita, na rede pública, será destinada àqueles que não tiveram acesso ou continuidade de estudos no Ensino Fundamental e Médio na idade própria.

Art. 85 - O Estado estabelecerá convênios com empresas e órgãos públicos de modo a disponibilizar aparelhagem e demais condições para recepção de programas de tele-educação no local de trabalho, garantindo também professores qualificados para acompanhar e avaliar os educandos.

Art. 86 - O Poder Público deverá garantir oferta regular de ensino noturno, nos mesmos padrões de qualidade do diurno, em escola próxima dos locais de trabalho ou residência.

Art. 87 - No uso do tempo curricular, as escolas deverão assegurar aos alunos oportunidades educacionais apropriadas que considerem:

I - os mínimos de carga horária definidos pela legislação;

II - as características, interesses, condições de vida e de trabalho do aluno, especialmente sua disponibilidade de tempo e seu ritmo de aprendizagem.

Assim, vemos neste excerto dois discursos funcionando, um autoritário, pois é dever do Estado garantir o direito à educação, bem marcado nos trechos: "O Estado estabelecerá" e "O Poder Público deverá garantir". Aqui, o Estado, sobretudo, faz muito bem seu pal de legislar e emitindo o cumpra-se. Em contrapartida é dever do Estado também oferecer uma educação humanizadora, aos moldes de Paulo Freire, deste modo podemos perceber que há uma modalização na maneira de impor o ensino, como forma de manter uma unidade nacional, mas também com uma preocupação humana.

A educação de adultos, dentro desse contexto, torna-se mais que um direito: é a chave para o século XXI; é tanto consequência do exercício da cidadania como condição para uma plena participação na sociedade. Além do mais, é um poderoso argumento em favor do desenvolvimento ecológico sustentável, da democracia, da justiça da igualdade entre os sexos, do desenvolvimento socioeconômico e científico, além de ser um requisito fundamental para a construção de um mundo onde a violência cede lugar ao diálogo e à cultura de paz baseada na justiça. A educação de adultos pode modelar a identidade do cidadão e dar um significado à sua vida. A educação ao longo da vida implica repensar o conteúdo que reflita certos fatores, como idade, igualdade entre os sexos, necessidades especiais, idioma, cultura e disparidades econômicas. (V CONFINTEA, 1997) ${ }^{7}$

Os sentidos que vão se colocando é de um apagamento das falhas, mas como Pêcheux afirma que "só há causa daquilo que falha" (PÊCHEUX, 2009, p. 277), então essas falhas reclamam sentidos. $O$ Estado falha na alfabetização na idade certa e para que isso seja corrigido a língua vai produzindo sentidos: "A educação de adultos, dentro desse contexto, torna-se mais que um direito: é a chave para o século XXI", ou mesmo no excerto: "A educação de adultos pode modelar a identidade do cidadão e dar um

\footnotetext{
${ }^{7}$ Declaração de Hamburgo sobre Educação de Adultos. V Conferência Internacional sobre Educação de Jovens $\quad \mathrm{e} \quad$ Adultos. $\quad$ Disponível em http://forumeja.org.br/pi/sites/forumeja.org.br.pi/files/V\%20Confintea\%20Hamburgo\%201997.pdf. Acesso em 16 de setembro de 2012, às 18:17.
} 
significado à sua vida." E os sentidos vão se dando de modo que a falha vai sendo apagada por eufemismos. Os sentidos que emergem no simbólico é de uma normalidade e até mesmo de um altruísmo do Estado por se preocupar com a educação de jovens e adultos.

As leis para a educação de jovens e adultos funcionam pelo efeito de transparência que é próprio do Estado, como se tudo funcionasse pois está posto em lei. É como se estivesse tudo bem, pois o Estado está cumprindo com o seu papel. Esse efeito de evidência apaga o que o Estado já não cumpriu, que é o seu papel de promover a educação.

Temos ainda a Resolução Normativa da SEDUC n. 005/2011 - CEE/MT que diz em seu $\S 1^{\circ}$ do Art. $1^{\text {o }}$ :

A educação de Jovens e Adultos deverá pautar-se pelo respeito às condições sociais e econômicas, ao perfil cultural e aos conhecimentos dos estudantes, com vistas ao exercício da cidadania, à formação, para o mundo do trabalho e ao longo da vida.

As políticas educacionais visam em sua maioria à formação de cidadãos, ou seja, à formação de pessoas que cumpram seus deveres para depois terem direitos. "Formar para o mundo e para o trabalho", nos traz no discurso, uma formação utilitária. Assim pela educação formaremos trabalhadores, que serão futuros consumidores, que irão pagar impostos e sustentar a máquina capitalista. Se olharmos mais na opacidade discursiva, veremos que o Estado forma sujeitos atravessados por uma ideologia capitalista que já não serve ao Estado em si, mas à Economia. Somos reduzidos a objetos que produzem em detrimento do pensamento.

Ao pensar em educação, pensamos então no modo como esse saber será gerido. $\mathrm{O}$ que vai então gerenciar esse saber metalinguístico são as políticas de língua. Dessa forma, nos perguntamos como se dá o ensino de língua portuguesa na modalidade EJA, como o Estado regula este ensino? A princípio tomamos como materialidade discursiva o inciso I do Art. 208, da Constituição Federal:

Art. 208. O dever do Estado com a educação será efetivado mediante a garantia de:

I - ensino fundamental, obrigatório e gratuito, assegurada, inclusive, sua oferta gratuita para todos os que a ele não tiveram acesso na idade própria;

(Redação dada pela Emenda Constitucional n 14, de 1996)

A Constituição, pela lei, garante o ensino a todas as pessoas inclusive com relação àquelas que não receberam educação quando criança, exemplificado na parte "para todos os que a ele não tiveram acesso na idade própria", aqui entra em pauta a EJA. Se considerarmos o discurso em sua evidência, em uma primeira instância, podemos ter a ilusão de que está tudo funcionando como se deve, pois, o direito está assegurado em lei. No entanto, há aí um atravessamento ideológico, uma vez que assegurar a educação não é apenas um direito reservado, um dever do Estado, mas um modo de o Estado estabelecer as políticas de língua que levam à unidade nacional. Unidade que é cara também à língua e que nos remete à importância da gramatização. 
Isto se dá porque é papel do Estado, enquanto regulador, manter uma unidade linguística, segundo Orlandi (2002, p. 157): “a unidade do Estado se materializa em várias instâncias institucionais. Entre essas, a construção da unidade da língua, de um saber sobre ela e os meios de seu ensino (a criação das escolas e seus programas), ocupa posição primordial". Dessa forma, podemos ver que o Estado age através de seus aparelhos ideológicos, no nosso caso a escola, definindo/determinando o modo como o ensino de língua atende aos seus interesses. Acerca disto Althusser (1985, p. 70) diz o seguinte:

[...] devemos dizer que os Aparelhos Ideológicos do Estado funcionam principalmente através da ideologia, e secundariamente através da repressão seja ela bastante atenuada, dissimulada ou mesmo simbólica. (Não existe aparelho puramente ideológico). Desta forma, a Escola, as Igrejas "moldam" por métodos próprios de sanções, exclusões, seleção etc.

Isto posto, para pensarmos em como se dão as políticas de língua que balizam o ensino da língua portuguesa na EJA, lançamos mão de dois excertos. O primeiro está na proposta curricular para o primeiro segmento da EJA:

a área de Língua Portuguesa permeia as outras áreas do conhecimento. Nossa língua é o principal instrumento que temos para interagir com as outras pessoas, para termos acesso às informações, aos saberes, enfim, à cultura da qual fazemos parte. A importância da linguagem para os seres humanos não reside só nas possibilidades de comunicação que encerra. Por ser um sistema de representação da realidade, ela dá suporte também a que realizemos diferentes operações intelectuais, organizando o pensamento, possibilitando o planejamento das ações e apoiando a memória. (BRASIL. MEC, 2001, p. 51)

O segundo no documento intitulado: Por uma proposta curricular para o segundo segmento na EJA:

O trabalho com a oralidade e a escrita anima a vontade de explicar, criticar e contemplar a realidade, pois as palavras são instrumentos essenciais para a compreensão e o maravilhamento. Em uma série de circunstâncias, a necessidade do uso da linguagem se manifesta: da leitura do nome das placas à leitura de jornais, textos científicos, poemas e romances; da elaboração de um bilhete à comunicação e expressão de pensamentos próprios e alheios. Daí a importância de um curso que permita ao aluno da EJA ter uma experiência ativa na elaboração de textos, um curso que discuta o papel da linguagem verbal, tanto no plano do conteúdo como no plano da expressão. É importante que o aluno perceba que a língua é um instrumento vivo, dinâmico, facilitador, com o qual é possível participar ativamente e essencialmente da construção da mensagem de qualquer texto. (BRASIL. MEC, s/d, p. 302)

O que podemos perceber na materialidade significante é que os sentidos que se colocam em jogo vão ao encontro dos sentidos históricos que atravessam a língua desde a colonização: ensina-se a língua para dominar, para catequisar, para negociar. Ensina-se 
a língua com um propósito que está voltado para o uso da língua como instrumento, como se pudéssemos usá-la enquanto é necessário e depois guardá-la, como se fosse um acessório do sujeito: "Nossa língua é o principal instrumento que temos para interagir com as outras pessoas, para termos acesso às informações, aos saberes, enfim, à cultura da qual fazemos parte"; "É importante que o aluno perceba que a língua é um instrumento vivo, dinâmico, facilitador, com o qual é possível participar ativamente e essencialmente da construção da mensagem de qualquer texto." Ao tomar a língua como instrumento não se leva em conta a constituição do sujeito pela língua, são apagados os atravessamentos ideológicos e a língua se coloca enquanto algo fora do sujeito para apenas ser usada.

Podemos perceber que há também uma visão pragmática em funcionamento: "Por ser um sistema de representação da realidade, ela dá suporte também a que realizemos diferentes operações intelectuais, organizando o pensamento, possibilitando 0 planejamento das ações e apoiando a memória". A língua é vista como representação da realidade, apagando assim, as possiblidades de sentido, a metáfora, a polissemia.

Pelo viés da História das Ideias Linguísticas, podemos perceber como o ensino de língua é concebido pelo Estado na modalidade EJA. É seu dever legislar sobre a língua, pois só há nação se houver uma língua oficial, e pelos documentos analisados constatamos o dever cumprido do Estado através da Escola, pois é esta que coloca em prática tais ordens.

Com relação à pergunta proposta, pensando então o ensino de língua na modalidade EJA, “como o Estado, através destes documentos, regula o ensino de Língua no Brasil?”, vemos que o Estado possibilitou, de certa forma, a reinclusão de trabalhadores que, por um motivo ou outro, encontravam-se impossibilitados de estudar. Pensar que o Estado fez isso por altruísmo é tomar a língua enquanto transparente, ele o fez pois é seu dever manter uma unidade linguística, como modo de constituir uma nação civilizada, organizada, una. É através de leis que o Estado determina tais ações. Há alguém que legisla (o Estado) e há alguém que executa (a Escola), isto se dá desde o documento de fundação da Língua Portuguesa:

[...] a Comissão ${ }^{8}$ reconhece e proclama esta verdade: o idioma nacional do Brasil é a Língua Portuguesa [...]

Essa denominação, além de corresponder à verdade dos fatos, tem a vantagem de lembras, em duas palavras - Língua Portuguesa -, a história da nossa origem é a base fundamental da nossa formação de povo civilizado.

$\mathrm{O}$ que temos então são sentidos que ressignificam, fazendo funcionar $\mathrm{o}$ interdiscurso, no discurso oficial da modalidade EJA.

\footnotetext{
${ }^{8}$ Ver em GUIMARÃES, Análise de Texto - Procedimentos, Análise, Ensino. In: Denominação do Idioma Nacional do Brasil. 2011, p. 155
} 


\section{Referências bibliográficas}

ALTHUSSER, Louis. Aparelhos Ideológicos de Estado: nota sobre os aparelhos ideológicos de Estado. Trad. Bras. Rio de Janeiro: Edições Graal, 1985.

BRASIL. Ministério da Educação, Secretaria de Educação Média e Tecnologia. Parâmetros Curriculares Nacionais: ensino médio. Brasília: Ministério da Educação, 1999.

Educação para Jovens e Adultos: ensino fundamental: proposta curricular - $1^{\circ}$ segmento. São Paulo: MEC, 2001.

Alfabetização de jovens e adultos no Brasil: lições da prática. Brasília: UNESCO, 2008.

Por uma Proposta Curricular para o $2^{\circ}$ Segmento na EJA. Acesso em http://portal.mec.gov.br/seb/arquivos/pdf/vol1e.pdf. Acesso em 11/01/2017.

GUIMARÃES, Eduardo. Análise de Texto. Procedimentos, análises, ensino. Campinas: Editora RG, 2011.

MARIANI, B. Colonização Linguística. Campinas, SP: Pontes, 2004.

Políticas de Colonização Linguística. Letras, Universidade Federal de Santa

Maria, n. 27, dezembro, 2003. Disponível em https://periodicos.ufsm.br/letras/article/view/11900/7322. Acesso em jan. 2017.

MATO GROSSO. Secretaria de Estado de Educação. Diretrizes Educacionais: Estado de Mato Grosso. Cuiabá, Secretaria de Estado de Educação, 1998.

MORTATTI, Maria do Rosário Longo. Educação e Letramento. São Paulo: Unesp, 2004.

ORLANDI, E.P. Análise de Discurso: princípios e procedimentos. 10ª ed. Campinas, SP: Pontes Editores, 2012.

Língua Brasileira e outras histórias. Discurso sobre a língua e ensino no Brasil. Campinas, SP: Editora RG, 2009.

Política Linguística no Brasil. Campinas, SP: Pontes Editores, 2007.

Língua e conhecimento linguístico: para uma história das ideias no Brasil. São Paulo: Cortez, 2002.

Formação de um espaço de produção linguística: a gramática no Brasil. Em: História das Ideias Linguísticas no Brasil: construção do saber metalinguístico e 
constituição da língua nacional. Campinas, SP: Pontes; Cáceres, MT: UNEMAT Editora, 2001.

A Linguagem e seu funcionamento: as formas do discurso. Campinas, SP: Pontes, 1996.

PÊCHEUX, Michel. Semântica e Discurso: uma crítica à afirmação do obvio. Trad.

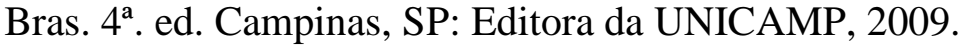

Artigo recebido em: setembro de 2016.

Aprovado e revisado em: janeiro de 2017.

Publicado em: abril de 2017.

Para citar este texto:

MAGIO, Maria Martins da Silva; SAMPAIO, Thalita Miranda Gonçalves. Políticas de língua e a educação de jovens e adultos. Entremeios [Revista de Estudos do Discurso, on-line], Seção Temática - Língua(gem) e Ensino, Programa de Pós-Graduação em Ciências da Linguagem (PPGCL), Universidade do Vale do Sapucaí (UNIVÁS), Pouso Alegre (MG), vol. 14, p. 203-212, jan. - jun. 2017.

DOI: http://dx.doi.org/10.20337/ISSN2179-3514revistaENTREMEIOSvol14pagina203a212 